\title{
Laudation for Dr. Rolf L. Zeisler: Hevesy Medal Award 2018 recipient
}

\author{
Richard M. Lindstrom ${ }^{1} \cdot$ R. Gregory Downing ${ }^{1} \cdot$ A. Chatt $^{2}$
}

Published online: 17 August 2018

(C) Akadémiai Kiadó, Budapest, Hungary 2018

Dr. Rolf L. Zeisler of the National Institute of Standards and Technology (NIST), Gaithersburg, Maryland, USA, was selected by the Hevesy Medal Award Selection Panel 2018 (HMASP-18) on 2017 November 30 to receive the Hevesy Medal Award 2018 in recognition of his work in the development and application of nuclear analytical methods to biosciences and environmental studies, and for the promotion of certified reference materials at the highest level of metrological science.

Dr. Zeisler was born on 1941 November 20 in Weissenfels, Sachsen-Anhalt, Germany. His family moved to Bavaria, where he studied at the Institute for Radiochemistry of the Technical University of Munich (TUM). He received his Ph.D. from TUM in 1974 on the application of activation analysis to study the corrosion products of metal implants in biological tissues. He held a postdoctoral fellowship at the Center for Trace Characterization at Texas A\&M University, College Station in 1975; and in 1978 joined NIST where he made his distinguished career. During a leave of absence in 1991-1995 he led the Chemistry Unit at the Seibersdorf laboratory of the International Atomic Energy Agency (IAEA), Vienna. He continued pursuing research at NIST as a Scientist Emeritus after his retirement in 2009 until his death on 2017 December 16.

Dr. Zeisler published more than 250 peer-reviewed papers and book chapters, co-authored with more than 200 scientists worldwide. He presented more than 100 invited talks and 200 additional professional scientific talks. His interests were unusually broad. He was alert to new developments in instrumentation that led him to improved analysis, notably novel methods to reduce data loss at high counting rates. His

\section{A. Chatt}

chatt@dal.ca

1 Chemical Sciences Division, National Institute of Standards and Technology, 100 Bureau Dr., Gaithersburg, MD 20899-8395, USA

2 Department of Chemistry, Trace Analysis Research Centre, Dalhousie University, 6274 Coburg Road, Room 212, P.O. Box 15000, Halifax, NS B3H 4R2, Canada recent work in digital gamma-gamma coincidence demonstrated that this approach can improve detection limits as well as specificity. He seized on the availability of a new cold neutron beam at the Kernforschungsanlage (KFA) in Jülich to demonstrate the virtues of this facility for prompt-gamma activation analysis (PGAA). This work led directly to the establishment of cold-neutron PGAA at NIST as a valuable technique for elemental analysis.

He continued studying trace elements in biological tissues. He was a leader in developing contamination-free sampling and storage methods in the National Environmental Specimen Bank (NESB), notably his cryogenic homogenization of tissue. Clean sampling combined with careful radiochemical neutron activation analysis resulted in the firm establishment of "normal" concentrations of chromium and other elements in human blood two orders of magnitude lower than previously believed. These advances enabled reliable sub-sampling of preserved materials, advanced specimen banking at the NIST's Marine Environmental Specimen Bank, and ultimately resulted in the NIST-National Oceanographic and Atmospheric Administration (NOAA) partnership in the establishment of the Hollings Marine Laboratory in Charlotte, North Carolina, USA.

A major part of his career was the concern with reference materials to ensure reliable analysis. At NIST he participated in the creation and analysis of over 100 NIST Standard Reference Materials (SRMs) and contributed over 1700 certification values for these SRMS. Dr. Zeisler was involved in interlaboratory comparisons with IAEA, Korea Research Institute of Standards and Science (KRISS), National Research Council of Canada (NRCC), and the Consultative Committee for Amount of Substance (CCQM). In recognition of outstanding contributions in the development of SRMs, he received the NIST Analytical Chemistry Division Chemical Metrology Award in 2007. While at the IAEA he coordinated a quality assurance intercomparison of analysis of NIST SRM 1570a Spinach, with results for more than 40 elements from 114 laboratories in the IAEA Member states. In recognition of his outstanding achievements in the development and application of nuclear analytical methods, he was awarded the 
Commemorative Medal of Charles University Prague in 1993.

Dr. Zeisler had a special interest in sampling as a source of analytical error, in several cases discovering unexpected inhomogeneity in NIST SRMs in the course of his certification analyses. Homogeneity has become increasingly important with developing techniques such as spark source mass spectrometry, in which a small sample is inferred to be representative of the whole. This culminated in SRM 2703 , a sediment material in which 29 constituent elements are certified at concentrations of unprecedented low $(0.7 \mathrm{mg})$ sample mass.

Dr. Zeisler later pursued quality assurance in air quality sampling in support of the US Environmental Protection Agencies Air Quality Research Objectives where he established micro-homogeneity of particulate matter (aerodynamic equivalent diameter of $2.5 \mu \mathrm{m}$ ). These efforts led to the reference material that standardizes US Government and private lab techniques required in air quality studies, examples: SRM 2783 Air Particulate on Filter Media, SRM 1649a Urban Dust and Reference Material (RM) 8785 Air Particulate Matter on Filter Media-the only RM of this kind.

Dr. Zeisler was active in organizing many international and national conferences on nuclear analytical methods and on their many applications. Notably, in 1989 he organized and chaired the fourth meeting on Nuclear Analytical Methods in the Life Sciences (NAMLS) at NIST, the first of many in this conference series to be held outside the IAEA. He was a longtime member of the International Committee on Activation Analysis (ICAA), which coordinates more than fifty-year series of Modern Trends in Activation Analysis (MTAA) conferences. He served repeatedly as Chair and Program Chair of both the Isotopes and Radiation Division and Biology and Medicine Division of the American Nuclear Society (ANS). For this and other services to the Society he received the ANS Radiation Science and Technology Award in 2009. He was involved in many other conferences through numerous organizations: their acronyms include ACS, ANS, APSORC, BERM, BESB, ICI, INCC, MARC, MTAA, NAC, NAMLS, NRC, and RadChem.

Dr. Zeisler was a strong advocate of information transfer not only through presentations and publications, but also through collaborations, worldwide training courses, and mentorships. In particular, he was host to $4 \mathrm{Ph} . \mathrm{D}$. thesis students and 13 post-doctoral fellows and visiting scientists. As well as organizing workshops to stimulate the education of the next generations of nuclear analytical scientists such as the Panel and Discussion on Manpower Requirements and Education in Nuclear Science-An International Perspective, held at the MARC-VI meeting in 2003.
In summary, Dr. Zeisler's research has been wideranging with a consistent emphasis on education, nuclear instrumentation, and methods development in the pursuit of metrological accuracy. His influence on his senior and junior colleagues has been notable. It is a pleasure for the JRNC Board of the Hevesy Award to honor Dr. Rolf L. Zeisler with the Hevesy Medal Award 2018.

Dr. Zeisler was nominated by Professor Dr. Georg Steinhauser (Gottfried Wilhelm Leibniz Universität, Germany), and co-sponsored by Professor Emile A. Schweikert (Texas A\&M University, USA) and Professor Zhifang Chai (Chinese Academy of Sciences, China).

The HMASP-18 consisted of Professor Amares Chatt (Dalhousie University, Canada, also Chair of JRNC Board of the Hevesy Award and Chair of HMASP-18), Professor Tibor Braun (L. Eötvös University, Hungary, also JRNC Board of the Hevesy Award), Dr. Samuel E. Glover (University of Cincinnati, USA, also representing MARC-XI), Professor Susanta Lahiri (Saha Institute of Nuclear Physics, India), Professor Boris F. Myasoedov (Russian Academy of Sciences, Russia), Dr. Yuichiro Nagame (Japan Atomic Energy Agency, Japan), Professor Pavel P. Povinec (Comenius University, Slovakia), Professor Syed Qaim (Forschungszentrum Juelich GmbH, Germany), and Dr. Zsolt Révay (Technische Universität München, Germany, also JRNC Board of the Hevesy Award). In accordance with the rules of the Award, a secret vote was conducted.

The Hevesy Medal and a Scroll honoring Dr. Rolf L. Zeisler (Fig. 1) was accepted on his behalf by his wife Dr. Susan Heller-Zeisler at the Eleventh international conference on Methods and Applications of Radioanalytical Chemistry (MARC-XI) held in Kailua-Kona, Hawai' $i$, USA, during 2018 April 08-13 (Fig. 2). She delivered the award lecture on his behalf based upon the speech outline that Dr. Zeisler had shared with her prior to his death.

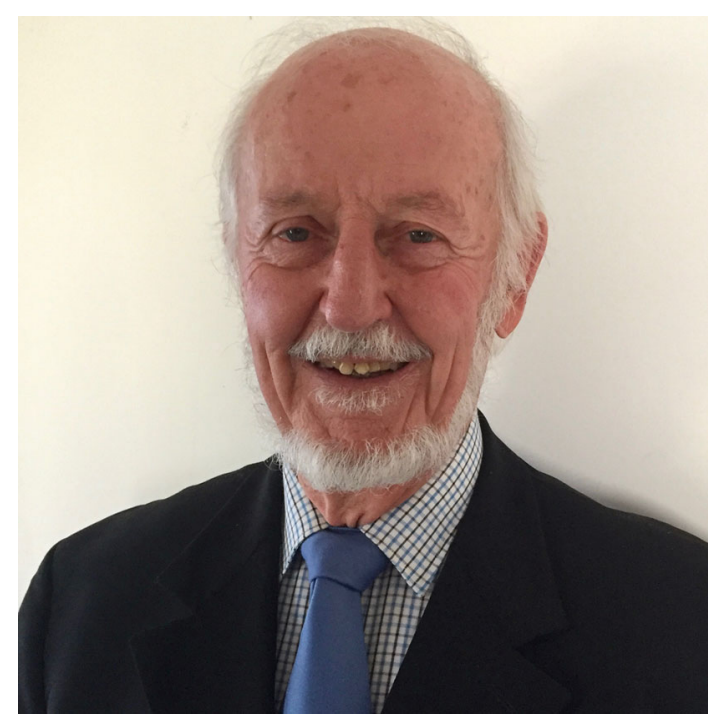

Fig. 1 Dr. Rolf L. Zeisler 


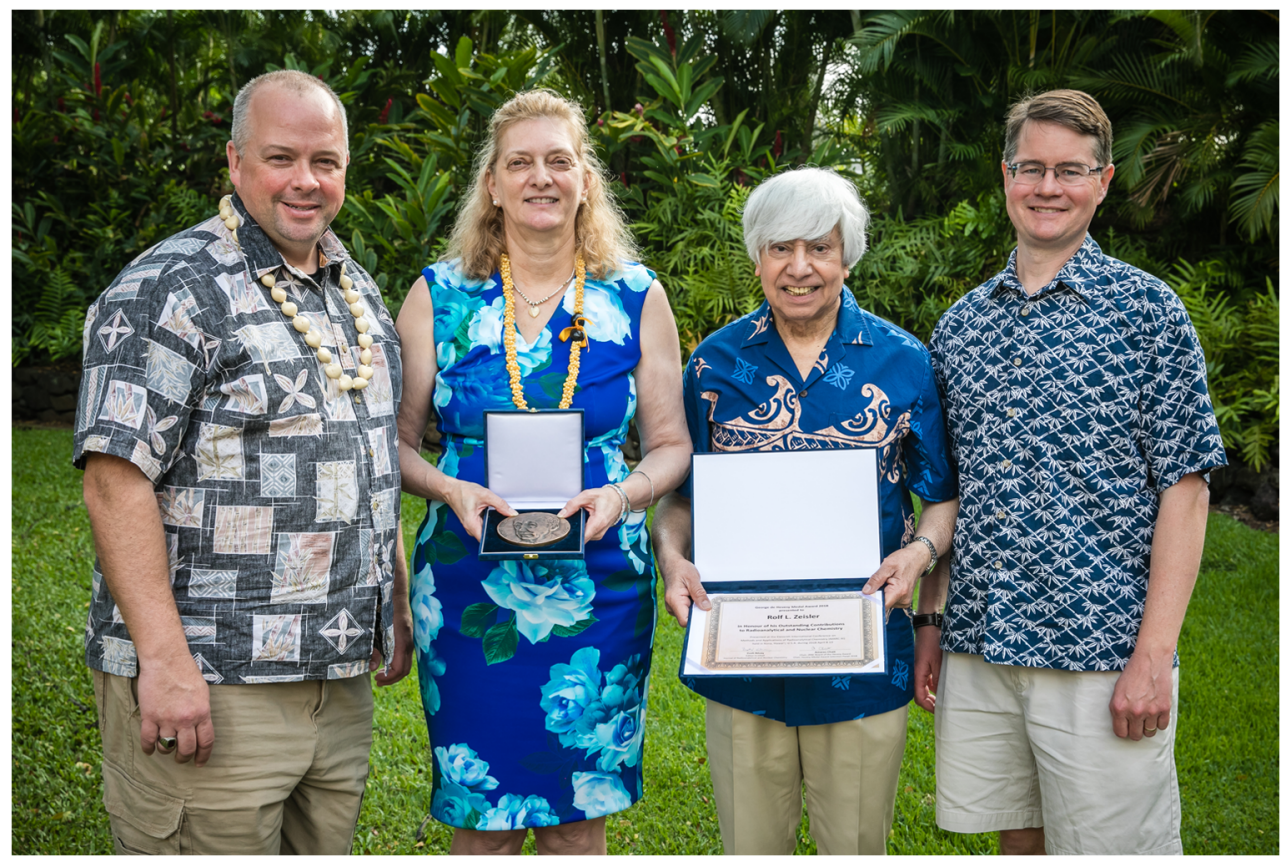

Fig. 2 From left to right: Dr. Samuel E. Glover, Dr. Susan Heller-Zeisler, Prof. Amares Chatt, and Dr. Stephen P. LaMont

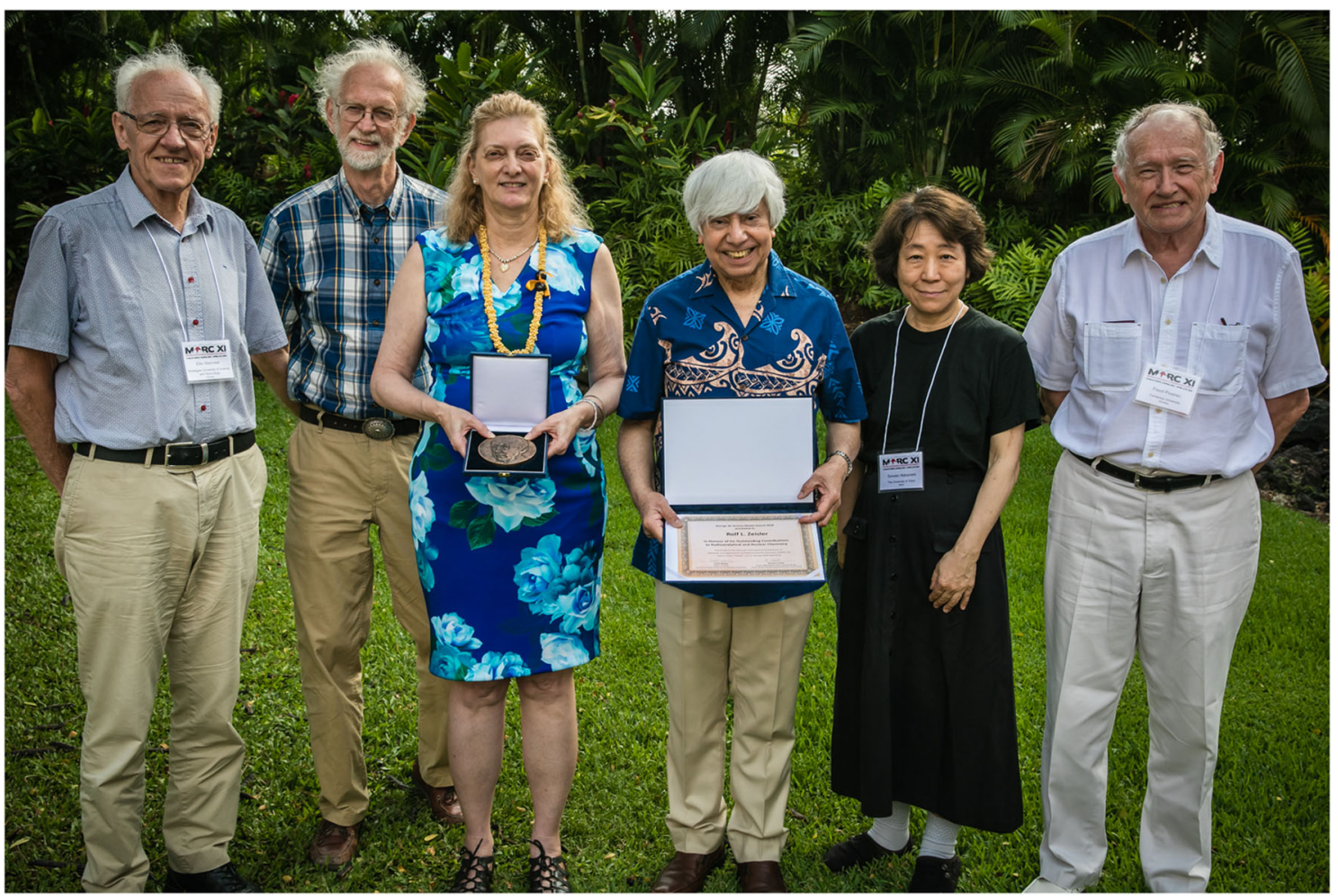

Fig. 3 From left to right (year of the award): Prof. Eiliv Steinnes (2001), Dr. Richard M. Lindstrom (2009), Dr. Susan Heller-Zeisler (on behalf of Dr. Rolf L. Zeisler, 2018), Prof. Amares Chatt (2001), Prof. Tomoko Nakanishi (2016), and Prof. Pavel P. Povinec (2017)

Several of the past Hevesy Medal Awardees attended MARC-XI and were present at the Hevesy Medal Award session (Fig. 3).
Photos are courtesy of: Dr. Susan Heller-Zeisler (Fig. 1) and Dr. Tibor G. Kocsor, JRNC (Figs. 2, 3). 